\title{
Editorial: Ethical Sensitivity - a Multidisciplinary Approach
}

\author{
Alida Naudé, Juan Bornman \\ Centre for Augmentative and Alternative Communication, University of Pretoria, Faculty of Humanities, Pretoria, South Africa
}

\section{Email address:}

alida@amtronix.co.za (A. Naudé), juan.bornman@up.ac.za (J. Bornman)

To cite this article:

Alida Naudé, Juan Bornman. Editorial: Ethical Sensitivity - a Multidisciplinary Approach. Humanities and Social Sciences. Special Issue: Ethical Sensitivity: A Multidisciplinary Approach. Vol. 4, No. 2-1, 2016, pp. 1-4. doi: 10.11648/j.hss.s.2016040201.11

Received: January 28, 2016; Accepted: March 21, 2016; Published: May 13, 2016

\begin{abstract}
The editorial provides an overview of this special edition. The leading guest editors aim to guide the reader through the various topics addressed in this collection of article papers related to ethics as presented by the individual authors. Topics are placed within the context of current available literature related to the philosophy of ethics, ethics education as well as ethics in practice. The value of focussing on personal growth and reflection as part of the ethical journey of discovery of self and others is highlighted and encouraged.
\end{abstract}

Keywords: Ethical Sensitivity, Multidisciplinary Approach, Ethics

\section{Overview}

It is with a sense of great excitement that we compiled this multidisciplinary collection of articles focused on ethics. The richness of the construct 'ehics', is seen in the compulation of the authors representing seven different professions across three different continents.

Why do we, as practitioners in the healthcare system behave ethically? Imagine what would happen if everyone did what they wanted, putting themselves first, without regard for the consequences... In a world without ethics, healthcare practices would not exist. However, healthcare practitioners profess to care about their clients, and caring is inescapably ethical [1]. Seedhouse [2], supports this notion with the statement that ethics lies at the heart of being a therapist. Society trusts therapists to provide expert services and commit themselves to acting in the best interest of their clients. Those therapists who consistently act in ways consistent with their stated high ethical standards are described as having integrity and are more likely to be trusted by their clients [3]. A strong sense of ethical responsibility is required to develop this fiduciary relationship with clients and therapists' behaviour must adhere to the ethical principles and rules that they have publicly agreed to follow by accepting their professional code of conduct. Nevertheless, the complex challenges that health practitioners have to face due to increasing accountability demands, resource challenges, global perspectives of standards and developing techniques, shifting knowledge and changing client relationships, is acknowledged.

The concept of ethics, also known as moral philosophy, dates back to Aristotle and ancient Greece. A distinction can be made between ethics and morals by referring to the origins of each word [4, 5]. 'Ethics' has its roots in the Greek term ethos, which refers to 'custom' or 'character', while morality' stems from the Latin term moris, which refers to 'conduct' or 'way of life'. From this perspective, morality refers to the actions that are taken on the basis of specific, culturally transmitted standards of right and wrong [6]. Colloquially, the word 'morals' usually applies to principles of right and wrong in personal behaviour. Morals are considered to be abstract, subjective and often based on personal or religious convictions. In contrast, ethics is the study (systematic reflection on and analysis) of general principles of human decision making and of right and wrong behaviour. At a more fundamental level, ethics is a method by which values are categorised and pursued [7]. It is about finding the balance between self-interest and group responsibility, and applies to both professional and business practices. Ethics is considered to be more practical than morals in that it is regarded as having shared principles that promote fairness.

Consequently, ethics is a valuable tool in the hand of the therapist who needs to decide on a course of action in terms of prevention, assessment, intervention and management [2]. Because the practice of therapeutic sciences is so intimately concerned with the personal vulnerabilities and quality of life 
of the client, it is subject to both legal and ethical restrictions, all of which have been designed to protect clients' interests. These ethical and legal principles compel health care practitioners to behave competently and ethically. It is, however, still important to recognise that therapeutic approaches are not universal programmes that are simply adjusted for so-called diverse groups. Each client has his/her own cultural identity as well as challenges that influence the management process. So, despite well-formulated legal and ethical restrictions, problem-solving still lies at the heart of professional practice and closely linked with ethical decision making [8]. Problem-solving is regarded as the most important cognitive activity for health care practitioners, including therapists, and without ethics to guide the process, professional actions would be random and reduce the effectiveness of the client management process [8].

Ethics in the therapeutic sciences have been influenced by the massive paradigm shift from the medical model of service delivery to the biopsychosocial model, which respects client autonomy and emphasises the importance of a therapist's ability to recognise not only how physiological factors influence the client's perceptions, expectations and behaviour, but also how psychological, social and environmental factors affect the way in which a client perceives his/her ability to function as a member of society $[9,10]$. Therapeutic approaches should therefore be adapted in accordance with the values and needs of clients from various socioeconomic, ethnic, racial and religious backgrounds and of a range of gender and sexual identities [11]. This is not always easy, since ethical issues embedded in the therapeutic sciences often result in a conflict between the ethical principle of autonomy and beneficence [12]. This paradigm shift to a biopsychosocial model [13] also allowed for a framework to be developed to describe and organise information on client functioning and disability. The International Classification of Functioning, Disability and Health (ICF) is a multipurpose classification framework designed to serve multi-disciplinary practitioners by providing a standard language and a conceptual basis for the definition and measurement of health and disability [10]. Therefore it crosses disciplinary boundaries while highlighting commonalities or shared focus, and allowing for the use of a shared language during multidisciplinary collaboration, such as this special edition.

The ethical behaviour of therapists, or the lack thereof, influences client's lives on a daily basis [15]. To make justifiable decisions, therapists must have a strong ethical orientation, which will be influenced by their level of moral development, level of professional competence, acquaintance with ethical principles and rules, as well as their general moral disposition and virtue [16]. Ethical theories as well as principles contained in the professional code of conduct facilitate the process of identifying and defining problems. They help healthcare practitioners to think systematically, encourage them to view issues from many different angles, and provide decision-making guidelines [17]. Combining insights from different perspectives presented in ethical theories might result in better solutions to ethical dilemmas. At the very least, it will encourage greater confidence in the choices therapists make.

Defining ethics and the importance thereof as the future for the healthcare profession is far from straightforward, particularly in the context of multidisciplinary collaboration. The articles in this special issue embrace a rich definition of ethics that incorporates different perspectives regarding the philosophical underpinnings of ethics, teaching and measuring of ethics skills, as well as ethics in clinical practice and in research.

\section{A Philosophical Perspective}

In the first article in this issue, Hofmeyr, considers, in fine detail, the enigma of ethical responsiveness from a philosophical perspective based on a Levinasian point of view. The reader in encouraged to look within themselves to understand their own strengths and weaknesses as the first step in the ethical decision-making process. This article resonates with other literature on the general behavioural model of ethical decision making (see for example Wittmer [18] that emphasises the importance of personal development as part of ethical growth and ethical decision making Likewise, Rest's Four-Component Model which is also placed at the centre of the general behavioural model, purports that ethical decisions are a product (in part) of sensitivity and perception of ethical issues as interpreted by a person and of the reasoning used to arrive at some conclusion about what to do in specific situations. In her article Hofmeyr reflects on how, if possible, to increase goodness in a person in order for them to extend it to others.

\section{Ethics Education}

The next two articles deal with the teaching of ethics, thereby opening the debate by raising the question: 'Can ethics be taught?' There is a significant body of research that challenges the potential for influencing the ethical development of established health care practitioners through continuing educational development programmes on the one hand and students in professional degree programmes on the other. If the focus of teaching ethics is to change moral character from 'bad' to 'good' or to guarantee the ethical behaviour of a person, teaching may indeed be futile. Rest [19] however, argues that a carefully constructed set of learning experiences can strengthen a healthcare practitioner's ability to be ethically responsible in the workplace.

Preparing health care practitioners, such as therapists, to discern ethical issues in complex work settings is considered a huge endeavour that should not be taken lightly [20]. Although it is accepted as best practice that the teaching of ethics should be structured, include policies and a code of practice, as well as a cultural understanding of the rules, this alone is not enough. Ethics teaching should result in persons who can differentiate between right and wrong, who can 
make difficult decisions and who are assertive enough to stand by the decisions they make.

Wiles, Murray, Baker, Berndt and Boshoff offer a systematic review as overview of student learning outcomes with regard to ethics teaching as reported in peer-reviewed allied health literature. Their outcome measures included Observed Learning Outcomes, Defining Issues Test, Readiness for Interprofessional Learning Scale, Attitudes to Health Professionals Questionnaire, Students Development Task Lifestyle Inventory, Socio-moral Reflection Measureshort form, free text questions and Likert scales. Wiles and colleagues also included transformative, constructivist, artsbased, interprofessional, problem-based and experiential learning approaches as pedagogy. Their review suggests that if ethics teaching is to be evidence-based, it should be based on theory but directly linked with real-life examples including controversial topics. Students should be allowed to reflect on different cases and given opportunity to discuss multiple views, guided by experienced practitioners.

Sevcik then describes a postgraduate ethics course thereby providing a guide on how to apply the recommendations of the review practically. In the program Sevcik highlights the importance of reflection and personal growth as fundamental elements to teaching ethics. The program is based on a focus that ethics permeates all aspects of practice. It includes examples such as an ethics autobiography assignment, an interview assignment and small group discussions. Morality and ethics are of such profound importance that it is impossible to understand the nature thereof in practice without reflection.

Next Naudé and Bornman offer a model to measure the efforts of teaching ethics in undergraduate students in professional healthcare degree courses. The focus of the measuring instrument relates to the first step in the process of ethical decision making and practice, namely ethical sensitivity. Ethical sensitivity is defined as the empathic interpretation of a situation by determining who is involved, what actions to take, and what possible reactions and outcomes might ensue. But can ethical sensitivity in health care practitioners be measured, and if so, how can this be done? This article describes the development and implementation of a multidisciplinary measure of ethical sensitivity for healthcare practitioners in the therapeutic sciences. Their research was limited to four allied health professions - audiology, occupational therapy, physiotherapy and speech-language therapy but they suggest that the same methodology can be applied to other health care practitioners.

\section{Ethics in Practice}

The last three articles in this special issue bring together a collection of papers concerned specifically with the everyday 'real-life' practicalities of ethical dilemmas. Three themes are addressed namely effective communication and negotiated decision-making, cultural competence in ethical decision making and finally ethical research conduct.

Communication is particularly important in establishing and maintaining the therapist-client relationship. Effective communication is related to greater mutual liking, empathy, rapport and trust. This, in turn, is related to client compliance and to more positive management outcomes. Alant sets out to discuss the ethical challenges facing healthcare practitioners in relation to communication and interactions involving individuals with severe memory and communication problems. She highlights the difficulties involved in professional-client engagement by applying some of the concepts in Levinas' theory of ethics, alluded to earlier by Hofmeyr. Healthcare practitioners are invited and encouraged to find new and unobtrusive ways of engaging as an essential part of working towards ethical practice.

In everyday practice, these healthcare proefssionals come into contact with divergent moral beliefs. They often find themselves in situations where conflict exists between the values systems of patients, health care institutions and practitioners. It takes conscious effort to rethink personal habits of acting and speaking, but doing this can promote professional services that are in the best interest of the client. Understanding how cultural groups differ and how differences can lead to conflict and misunderstanding will impact positively on the practitioner's interpersonal relationship with clients. Louw addresses cultural competence and ethical decision making by appraising the training and assessment of health care professionals, showing how cultural competence empower healthcare practitioners to provide the best service to their clients to ensure optimum outcomes.

In the final paper in this issue, Bryen addresses concerns about ethical practices in conducting research specifically involving people with disabilities. In addition to the wellknown ethical research principles and practices regarded as best practice, this paper highlights some new concerns and possible pitfalls for healthcare practitioners involved in research. Bryen discusses the impact of communication and information technology of the $21^{\text {st }}$ century on researcher conduct. She underscores the fact that ethics is not about researchers and practitioners doing what they believe is right, but rather about protecting the public, including its most vulnerable members.

\section{Conclusion}

Ethics underpins who we are as healthcare practitioners, what we think and how we act. We hope that readers find this collection of articles papers instructive and thought provoking. We trust that the focus on personal growth and reflection guides all readers on the path of self-discovery with noticeable benefits. Finally, we are grateful to the authors and the anonymous reviewers who generously contributed their time and expertise to this special issue.

\section{References}

[1] Pera S, Van Tonder S. Ethics in Healthcare. 3rd ed. Younge G, editor. Lansdowne: Juta; 2011. 
[2] Seedhouse D. Ethics. The heart of health care. Chichester: John Wiley \& Sons Ltd.; 1998.

[3] Pera S. The moral and ethical foundation of nursing. In: Oosthuizen A, Van der Wal D, editors. Ethics in healthcare. 3rd ed. Lansdowne: Juta; 2011.

[4] Day LA. Ethics in media communications: Cases and controversies. 4th. Belmont CA: Thomson/Wadsworth; 2003.

[5] Horner J. Morality, ehtics, and law: Introductory concepts. Semin Speech Lang. 2003; 24: 263-74.

[6] Louw B, Williams L, Scherer. SLPs and AUDs go global: a research-based cross-linguistic curriculum. CAPCSD annual conference. 2013.

[7] Landauer J, Rowlands J. The importance of phylosophy [Internet]. 2001. Available from: http://www.importanceofphilosophy.com/Ethics_Main.html

[8] Jonassen DH. Toward a design theory of problem solving. Educ Technol reaseach Dev. 2000; 48(4): 63-85.

[9] Smit R. In search of "non-disease." Br Med J. 2002; (324): $883-5$.

[10] World Health Organization. The ICF: an overview. Geneva: WHO; 2001.

[11] Kottler J. On Being a Therapist. 4th ed. San Francisco: JosseyBass; 2010.
[12] Lützén K, Nordin C, Brolin G. Conceptualization and instrumentation of nurses moral sensitivity in psychiatric practice. Int J Methods Psychiatr Res. 1994; 4(4): 241-8.

[13] Bebeau M, Rest J, Yamoor C. Measuring dental students' ethical sensitivity. J Dent Educ. 1985; 49(4): 225-35.

[14] Rest J. Moral development: advances in research and theory. New York: Praeger; 1986.

[15] Asenjo B, More K. Ethics for Speech Language Pathologists \& Audiologists. 2009. p. 1-59.

[16] Coulehan J. Today's professionalism: engaging the mind but not the heart. Acad Med. 2005; 80(10): 892-8.

[17] Califano J. The triumph and tragedy of Lyndon Johnson. New York: Simon Schuster; 1991.

[18] Wittmer D. Ethical sensitivity and managerial decisionmaking: an experiment. J public Adm Res theory. 1992; 2(4): 443-62.

[19] Rest J. Morality. In: Flavell J, Markman E, editors. Carmichael's manual of child psychology. 4th ed. New York, NY: Wiley; 1982. p. 556-629.

[20] McNeel S. College teaching and student moral development. In: Rest JR, Narvaez D, editors. Moral development in the professions: psychology and applied ethics. New York: Psychology Press; 1994. 